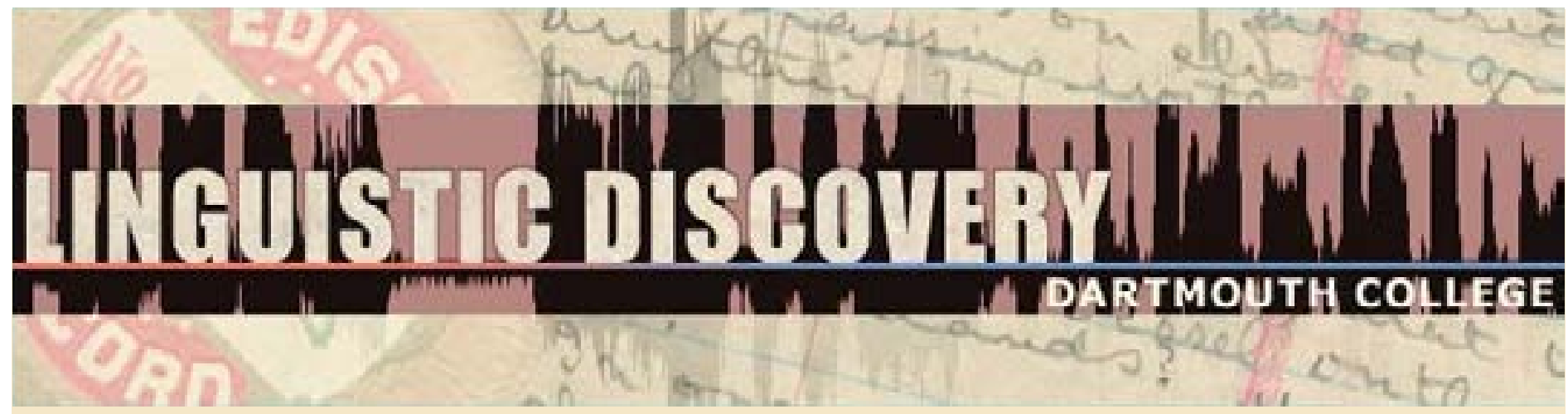

Volume 1

Issue 2 2002

\section{A New Passive in Kaqchikel}

George Aaron Broadwell and Lachlan Duncan

University at Albany, State University of New York

doi: 10.1349/PS1.1537-0852.A.161

url: http://journals.dartmouth.edu/cgi-bin/WebObjects/ Journals.woa/1/xmlpage/1/article/161 


\title{
A New Passive in Kaqchikel
}

\author{
George Aaron Broadwell and Lachlan Duncan \\ University at Albany, State University of New York
}

This paper contrasts two passives in Kaqchikel, a Mayan language spoken in Guatemala. The first passive, which we label the 'standard passive' is already well-attested in the literature. However, the second passive, which we label the 'ki-passive', has not been previously described. A verb in the ki-passive shows active morphology, with ergative agreement for a third person plural subject, as would be appropriate for a verb with an impersonal 'they' subject.

In Kaqchikel, however, we argue that this verb form has evolved into a new passive. The paper compares the properties of the standard passive and the ki-passive, and argues that while they involve the same change of grammatical relations, the two passives differ in the discourse functions they assign to the agent and patient.

\section{Introduction ${ }^{1}$}

In Kaqchikel, a Mayan language of highland Guatemala, the passive voice is wellrepresented with a variety of constructions. This paper addresses the discovery of a new Kaqchikel passive which we call the $k i$-passive and discusses some ways in which it differs from the previously recognized passives.

\subsection{The Active}

The active voice for root transitives (RTV) is unmarked (Dayley 1978).

\footnotetext{
${ }^{1}$ Kaqchikel is a Mayan language spoken by about half a million people in Guatemala. This paper reports on the dialect of Patzicía as spoken by Alberto Esquit Choy. The paper uses the conventions of the national orthography, in which $\langle\mathrm{x}\rangle=\mathrm{a}$ voiceless alveopalatal sibilant (IPA [S]), $<\mathrm{tz}\rangle=\mathrm{a}$ voiceless dental affricate (IPA [ts]), $<\mathrm{ch}>=$ a voiceless alveopalatal affricate (IPA [t]]), $<\ddot{a}>=\operatorname{schwa~(IPA~[ə]),~}<\mathrm{q}>$ is a uvular stop and apostrophe $=$ glottal stop (following a vowel) or glottalization (following a consonant). Lax vowels are indicated by diaresis. Kaqchikel dialects differ in the number of phonemic vowels. Although the national orthography represents ten distinct vowels, the Patzicía dialect has six $(a, \ddot{a}, e, i, o, u)$ and we write only those vowels here.

Glosses use the following abbreviations: $\mathrm{A}=$ absolutive, $\mathrm{af}=$ actor focus, $\mathrm{cl}=$ personal classifier (markers of the age and sex of human referents), $c$ com $=$ completive aspect, $\mathrm{E}=$ ergative, inc $=$ incompletive aspect, $\mathrm{p}=$ plural, pass $=$ passive, $\mathrm{s}=$ singular.

Most other work on Kaqchikel (Dayley 1978, García Matzar and Guaján Rodríguez 1997) uses an explicit null symbol (Ø) corresponding to the 3rd person singular absolutive in the segmentation of verbal morphology. Because we prefer a rule-based morphology (Anderson 1992, Beard 1995), we see null morphemes as theoretically problematic and have omitted them from our segmentation and glossing.

We thank our consultant Alberto Esquit Choy, who not only provided all the Kaqchikel data, but also contributed cogent suggestions for this analysis. We also thank Agustina Teleguario Ejcalou de Esquit, a speaker of the Patzún dialect of Kaqchikel, for providing us with comparative data on her dialect. Finally, we thank Farrell Ackerman, Nora England, Jack Martin, Timothy Smith, and an anonymous reviewer for helpful comments on this paper.
} 
$\begin{array}{lll}\text { (1) Ri achin } & \text { X-u-ch'äy } & \text { ri tz'i' } \\ \text { the man } & \text { COM-3sE-hit } & \text { the dog }\end{array}$

'The man hit the dog.'

For derived transitives (DTV), the active voice root is suffixed with $/-\mathrm{Vj} /$, generally called the transitive marker (Dayley 1978). The quality of the vowel in this suffix is not synchronically predictable, and so must be specified in the lexical entry of a verb.

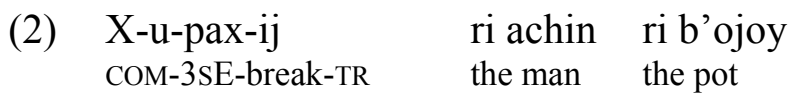

'The man broke the pot'

\subsection{The Agreement System}

Kaqchikel verb agreement works on an ergative/absolutive basis. The agreement markers are shown in the following table:

\begin{tabular}{l|ll|l}
\multicolumn{2}{c}{} & \multicolumn{2}{l}{ Ergative } \\
& Preconsonantal & Prevocalic & \multicolumn{2}{l}{ Absolutive } \\
\hline $\mathbf{1} \mathbf{~ s g}$ & nu- & w- & in- \\
$\mathbf{2} \mathbf{~ s g}$ & a- & aw- & at- \\
$\mathbf{3} \mathbf{~ s g}$ & ru- $/ \mathrm{V}-$ & r- & $\emptyset$ \\
& u- $/ \# \mathrm{C}-$ & & \\
$\mathbf{1} \mathbf{~ p l}$ & qa- & q- & oj- \\
$\mathbf{2}$ pl & i- & iw- & ix- \\
$\mathbf{3}$ pl & ki- & k- & e-
\end{tabular}

Examples:

(3) X-in-ki-k'utuj.

COM-1sA-3PE-ask

'They asked me.'

(4) X-e-wär.

COM-3PA-sleep

'They slept.'

(5)

$\begin{array}{lll}\text { Y-e-ru-näq } & \text { kan } & \text { ri alab'om. } \\ \text { INC-3PA-3sE-bother } & \text { DIR } & \text { the children }\end{array}$

'She was bothering the children.' 


\section{The Passives}

Several passive types, based on morphological, phonological, and syntactic variation, are found in Kaqchikel. We must recognize three distinct passives: the standard passive, the perfective passive, and the ki-passive. In this paper, we focus on a comparison of the standard passive and the ki-passive.

\subsection{The Standard Passive}

The standard passive for root transitive verbs (RTV) is marked by either zero or change of vowel. Normally a transitive verb root will have the shape CVC, where the vowel is lax. To mark a root as passive, the vowel changes from lax to tense. Compare the following

$\begin{array}{lll}\text { Ri achin } & \text { x-u-ch'äy } & \text { ri tz'i' } \\ \text { the man } & \text { COM-3sA-3sE-hit } & \text { the dog }\end{array}$

'The man hit the dog.'

$\begin{array}{lccc}\text { Ri tz'i' } & \text { X-ch'ay } & \text { r-oma' } & \text { ri achin } \\ \text { the dog } & \text { COM-hit:PASs } & \text { 3sE-by } & \text { the man } \\ \text { 'The dog was hit by the man.' } & & \end{array}$

In this example, notice that ri achin 'the man' is subject of the active verb and triggers ergative agreement. In the passive, by contrast, ri achin appears as the possessor of a relational noun. ${ }^{2}$ Third person singular absolutive arguments trigger no overt agreement, so there is no agreement with $r i t z$ ' $i$ ' 'the dog' in either the active or the passive.

Our primary consultant, Alberto Esquit Choy, speaks a dialect of Kaqchikel with only six phonemic vowels. In his dialect the tense/lax contrast is only found for the low vowel pair /a/ vs. /ä/. As a consequence, many root transitives with a non-low vowel show identical active and passive roots:
Ri a Juan
x-u-tij ri-wä'y.
the cl Juan
COM-3SE-eat the tortilla

'Juan ate the tortilla.'

\begin{tabular}{|c|c|c|}
\hline $\begin{array}{l}\text { Ri wä'y } \\
\text { the tortilla }\end{array}$ & $\begin{array}{l}\text { X-tij } \\
\text { COM-eat:PASS }\end{array}$ & $\begin{array}{l}\text { r-oma' } \\
\text { 3sE-by }\end{array}$ \\
\hline
\end{tabular}

\footnotetext{
${ }^{2}$ Several notions typically conveyed by adpositions in other languages are expressed in Mayan through the use of relational nouns. They express location and logical relationships and generally show ergative agreement with NP that follows.
} 
For the passive of a derived transitive verb (DTV), the standard passive is marked with $/-\mathrm{Vx} /$, where the vowel of the suffix is a lax version of that found in the active.

$\begin{array}{lll}\text { X-u-pax-ij } & \text { ri achin } & \text { ri b'ojoy } \\ \text { cOM-3sE-break-TR } & \text { the man } & \text { the pot }\end{array}$

'The man broke the pot'

$\begin{array}{llll}\text { Ri b'ojoy } & \text { x-pax-ix } & \text { r-oma' } & \text { ri achin } \\ \text { the pot } & \text { COM-break-PASS } & \text { 3sE-by } & \text { the man }\end{array}$

'The dog has been grabbed by the man.'

\subsection{The Perfective Passive}

Kaqchikel also has a perfective passive that emphasizes the result or the completion of an activity (Dayley 1981). It marks the verb root with the suffix /-Vtäj/, where the vowel matches that found in the active.

$\begin{array}{llll}\text { Ri tz'i' } & \text { X-chap-atäj } & \text { r-oma' } & \text { ri achin } \\ \text { the dog } & \text { COM-grab-PASS } & \text { 3sE-by } & \text { the man }\end{array}$

'The dog has been grabbed by the man.'

$\begin{array}{llll}\text { Ri b'ojoy } & \text { x-pax-itäj } & \text { k-oma' } & \text { rije } \\ \text { the pot } & \text { COM-break-PASS } & \text { 3PE-by } & \text { they }\end{array}$

'The pot has been broken by them.'

This passive seems to differ from the standard passive only in aspect, being interpreted something like an English perfect. We will not focus on the perfective passive in this paper.

\subsection{The ki-Passive}

The ki-passive, which has not been previously discussed, is substantially different from the above passives in morphology and in agreement marker behavior, as indicated by the following:

$\begin{array}{llll}\text { Ri tz'i } & \text { X-ki-chäp } & \text { r-oma' } & \text { ri achin } \\ \text { the dog } & \text { COM-PASS-grab } & \text { 3sE-by } & \text { the man }\end{array}$

'The dog was grabbed by the man.'

$\begin{array}{llll}\begin{array}{l}\text { Ri b'ojoy } \\ \text { the pot }\end{array} \quad \text { COM-PASS-break-TR } & \text { r-oma' } & \text { rija' } \\ \text { 'The pot was broken by him.' } & & \text { him }\end{array}$

Syntactically, the clause appears to be passive in that there is one direct argument, the 
subject, and a relational noun phrase with the demoted agent. However, the verbal morphology has undergone considerable change. The ki-passive takes an active transitive verbal suffix instead of the expected passive suffix. ${ }^{3}$ In addition, this passive is marked, unexpectedly, by the third person plural ergative agreement marker /ki-/.

\section{Properties of the ki-Passive}

\subsection{Agreement and the ki-Passive}

Although the $/ \mathrm{ki}-/$ morpheme that appears in these examples looks like the 3rd person plural ergative agreement marker, that cannot be its synchronic function in the ki-passive.

$\begin{array}{llll}\text { Ri b'ojoy } & \text { x-ki-pax-ij } & \text { r-oma' } & \text { rija' } \\ \text { the pot } & \text { COM-PASS-break-TR } & \text { 3sE-by } & \text { him }\end{array}$

'The pot was broken by him.'

$\begin{array}{llll}\text { Ri b'ojoy } & \text { X-ki-pax-ij } & \text { k-oma' } & \text { rije' } \\ \text { the pot } & \text { COM-PASS-break-TR } & \text { 3PE-by } & \text { them }\end{array}$

'The pot was broken by them.'

These examples show that the ki-passive construction may be used with both a singular and a plural third person NP in the relational noun phrase (RNP). Thus the demoted agent in the RNP does not agree with the third person plural ergative pronominal $/ \mathrm{ki}-/$.

Non-third-person agents are also allowed with the ki-passive, giving further evidence that the $/ \mathrm{ki}-/$ which occurs in these forms does not function as an agreement marker.

$\begin{array}{llll}\text { Ri b'ojoy } & \text { x-ki-pax-ij } & \text { q-oma' } & \text { roj } \\ \text { the pot } & \text { COM-PASS-break-TR } & \text { 1PE-by } & \text { us } \\ \text { 'The pot was broken by us.' } & & \end{array}$

$\begin{array}{llll}\text { Ri tz'i } & \text { x-ki-tz'et } & \text { aw-oma' } & \text { rat } \\ \text { the dog } & \text { COM-PASS-see } & \text { 2SE-by } & \text { you }\end{array}$

'The dog was seen by you (sg).'

Local persons are also acceptable as subjects of the ki-passive:

$\begin{array}{llll}\text { Rin } & \text { X-in-ki-tz'et } & \text { aw-oma' } & \text { rat. } \\ \text { I } & \text { COM-1sA-PASS-see } & \text { 2sE-by } & \text { you } \\ \text { 'I was seen by you.' } & & \end{array}$

\footnotetext{
${ }^{3}$ In fact the occurrence of the $/-\mathrm{Vj} /$ suffix in ki-passives seems to show that it does not synchronically have the status of a transitive marker in Kaqchikel. We have retained the gloss TR since the status of this suffix is not central to our argument, but we suspect that this analysis must be revised.
} 


\begin{tabular}{|c|c|c|}
\hline $\begin{array}{l}\text { Rat } \\
\text { you }\end{array}$ & $\begin{array}{l}\text { X-at-ki-tz'et } \\
\text { COM-2sA-PASS-see }\end{array}$ & $\begin{array}{l}\text { W-oma' } \\
\text { 1sE-by }\end{array}$ \\
\hline \multicolumn{3}{|c|}{ 'You were seen by me.' } \\
\hline oj & $\begin{array}{l}\text { x-oj-ki-tz'et } \\
\text { COM-2PA-PASS-see }\end{array}$ & aw-oma' \\
\hline & e seen 1 & \\
\hline
\end{tabular}

\subsection{A Possible Ambiguity}

In many cases, the examples of ki-passives that we cite are subject to two readings, one transitive and one intransitive. This ambiguity arises from two facts: 1.) the $/ \mathrm{ki}-/$ morpheme can be either a passive marker or a $3^{\text {rd }}$ plural ergative agreement marker, and 2.) -oma' is a relational noun that may correspond both to 'by' and to 'because'.

So, for instance, the following example has two possible readings:

$$
\begin{array}{lccc}
\text { Rin } & \text { X-in-ki-b'a' } & \text { r-oma' } & \text { ri tz'i'. } \\
\text { the dog } & \\
\text { I } & \text { COM-1sA-PASS-bite } & \text { 3sE-by } & \text { PASSIVE READING } \\
\text { 'I was bitten by the dog.' } & & &
\end{array}
$$

$\begin{array}{lccc}\text { Rin } & \text { X-in-ki-b'a' } & \text { r-oma' } & \text { ri tz'i'. } \\ \text { I } & \text { COM-1sA-3PE-bite } & \text { 3sE-because } & \text { the dog } \\ \text { 'They bit me because of the dog.' } & \text { TRANSITIVE READING }\end{array}$

As is evident, the truth-conditions of the two readings are quite distinct. The passive reading cannot be derived in some way from the transitive reading. In what follows, we focus on the passive interpretation of these examples.

\subsection{The Subject Status of the Patient in the ki-Passive}

Because Kaqchikel has an ergative/absolutive agreement system, absolutive markers are used for both objects of transitive verbs and subjects of intransitive verbs. So when we look an example like the following, we cannot tell from the agreement whether ' $\mathrm{I}$ ' is in the subject or the object position.

$$
\begin{aligned}
& \begin{array}{llll}
\text { Rin } & \text { x-in-ki-b'a' } & \text { r-oma' } & \text { ri tz'i'. } \\
\text { I } & \text { COM-1sA-PASS-bite } & \text { 3sE-by } & \text { the dog }
\end{array} \\
& \text { 'I was bitten by the dog.' PASSIVE READING }
\end{aligned}
$$

Two possibilities arise. One possibility is that the grammatical relations are like those implied by the English translation: the patient is in subject position and the verb is intransitve. Another possibility is that the patient is in object position, the verb is transitive, and the subject position is occupied by an arbitrary $3^{\text {rd }}$ person plural subject. As we have just said, the morphology of these examples is compatible with both 
hypotheses.

The word order tells us very little about the grammatical relations in such examples. In Broadwell (2000) the topic is discussed in more detail, but it is sufficient to say here that all the logically possible orders of patient, verb, and agent phrase are possible in (25). So far as we can tell, there are no word-order possibilities that distinguish the two hypotheses.

We turn instead to two somewhat subtler tests for subject. The first strategy involves using subject-oriented relational noun phrases. We find that a phrase like rik' $i$ rurayb'äl 'because of his/her desire' or 'voluntarily' consistently modifies subjects.

$$
\begin{array}{lllll}
\text { A Juan } & \text { x-u-tz'ub'-aj } & \text { xta Maria } & \text { r-ik'i } & \text { ru-rayb'äl. } \\
\text { CL Juan } & \text { COM-3sE-kiss-TR } & \text { CL Maria } & \text { 3sE-because:of } & \text { 3sE-desire } \\
\text { 'Juan kissed Maria voluntarily' } & \multicolumn{2}{c}{\text { ACTIVE }} \\
\text { (=Juan's choice) } & \multicolumn{2}{l}{}
\end{array}
$$

$\begin{array}{llllll}\text { Xta Maria } & \text { x-tz'ub'-äx } & \text { r-oma' } & \text { a Juan } & \text { r-ik'i } & \text { ru-rayb'äl. } \\ \text { CL Maria } & \text { COM-kiss-PASS } & \text { 3sE-by } & \text { CL Juan } & \text { 3sE-because:of } & \text { 3sE-desire } \\ \text { 'Maria was kissed by Juan voluntarily.' } & & \text { STANDARD PASSIVE }\end{array}$

When we examine the ki-passive, we find that rik'i ru-rayb'äl modifies the patient:

$$
\begin{aligned}
& \text { Xta Maria } \quad \text { x-ki-tz'ub'-aj r-oma' a Juan r-ik'i ru-rayb'äl. } \\
& \text { CL Maria COM-PASS kiss-TR 3sE-by CL Juan 3sE-because:of 3sE-desire } \\
& \text { 'Maria was kissed by Juan voluntarily.' KI-PASSIVE } \\
& \text { (= Maria's choice.) }
\end{aligned}
$$

Here, the adverbial expression 'voluntarily' modifies the subject of the ki-passive, 'Maria.' This suggests that the patient in the ki-passive construction is, in fact, the subject.

The second strategy in identifying the subject of the passive is to examine complement clauses. The complementizer chi 'that' is obligatory in cases when the matrix subject is different than the embedded subject. If the matrix and embedded subjects are identical, however, then the complementizer may be omitted. Consider the following examples: ${ }^{4}$

$$
\begin{array}{lllll}
\text { A Juan } & \text { n-r-ajo' } & \text { (chi) } & \text { n-u-loq' } & \text { saqmolo. } \\
\text { CL Juan } & \text { INC-3SE-want } \\
\text { 'Juan wants to buy eggs. } & \text { (COMP) } & \text { INC-3sE-buy } & \text { eggs }
\end{array}
$$

\footnotetext{
${ }^{4}$ Although some of these examples involve infinital complements and other tensed complements, there is no corresponding morphological difference in Kaqchikel.

${ }^{5}$ In general the complementizer would be omitted here. There is a subtle semantic effect of inserting the complement, roughly comparable to the difference between infinitival and tensed complements in English. Thus the readings of this example without the complementizer might be paraphrased 'John wishes to buy
} 


\begin{tabular}{|c|c|c|c|}
\hline $\begin{array}{l}\text { A Juan } \\
\text { CL Juan }\end{array}$ & $\begin{array}{l}\text { n-r-ajo' } \\
\text { INC-3sE-want }\end{array}$ & $\begin{array}{l}\text { chi } \\
\text { COMP }\end{array}$ & $\begin{array}{l}\text { (rija') } \\
\text { (he) }\end{array}$ \\
\hline
\end{tabular}

'Juan wants him $_{\mathrm{j}}$ to buy eggs.'

\begin{tabular}{|c|c|c|}
\hline an & n-r-ajo' & rija' \\
\hline
\end{tabular}

A coreferent argument in the lower clause other than the subject does not license complementizer omission:

$\begin{array}{lllllll}\text { A Juan } & \text { x-u-b'ij } & \text { ch-w-e } & \text { chi } & \text { ja } & \text { ri tz'i' } & \text { x-ba'-o'. } \\ \text { CL Juan } & \text { COM-3SE-tell } & \text { PREP-1sE-to } & \text { COMP } & \text { FOC } & \text { the dog } & \text { cOM-bit-AF }\end{array}$

' $\operatorname{Juan}_{1}$ told me that it was the dog that bit him $1 . '$
*A Juan
x-u-b’ij
ch-w-e
$\varnothing \quad$ ja
ri tz'i'
x-ba'-o'.
CL Juan
COM-3SE-tell PREP-1sE-to
FOC the dog
COM-bit-AF
'Juan ${ }_{1}$ told me that it was the dog that bit him ${ }_{1}$.'

Use of complementizer, then, constitutes a subject test. The complementizer is omissible if the subject of its clause is the same as the subject of the higher clause. By this test, the patients of both the standard passives (34a) and the ki-passives qualify (34b) as subjects:
A Juan $\quad \mathrm{x}-\mathrm{u}-\mathrm{b}^{\prime} \mathrm{ij}$
ch-w-e
(chi)
x-b'a-x
r-oma'
ri tz'i'
CL Juan COM-3SE-tell
PREP-3SE-to
(СOMP)
cOM-bite PASS 3sE-by
the dog
'Juan ${ }_{1}$ told me that he ${ }_{1}$ was bitten by the dog.' STANDARD PASSIVE
A Juan x-u-b'ij ch-w-e
(chi) $\quad \mathrm{x}-\mathbf{k i}$-b'a'
COM-PASS-bite
$\begin{array}{ll}\text { r-oma' ri tz'i' } \\ \text { 3sE-by } & \text { the dog }\end{array}$ 'Juan ${ }_{1}$ told me that he 1 was bitten by the dog.'
KI-PASSIVE

\section{Cross-linguistic Comparison}

\subsection{The Creek Impersonal Plural Marker, /-ho-/}

Martin (2000:387-9) describes a related construction in Creek, a Muskogean language spoken in Oklahoma and Florida. The Creek impersonal plural is used for valencyreducing and voice-marking functions. In general terms, its function is to indicate that the specific identity of an agent is unimportant, for example, when referring non-

eggs'. The example with the complementizer is approximately 'John wishes he could/would buy eggs'. In the second reading, the matrix subject seems to have less control over the event in the complement. 
anaphorically to people in general, or when referring to backgrounded subjects.

The impersonal plural marker ho- is always grammatically plural, even though the sense may be singular. The impersonal plural construction is translated into English as a passive due to the detopicalizing of its subject, yet differs from a true passive in that the verb's object remains case marked as an object, not as a subject. Consider the following examples, where 'boiling water' and 'Wolf' remain marked with the oblique case:

$$
\begin{array}{lll}
\text { oymó:łki-n } & \text { yahá-n } & \text { akál }<\text { ho }>\text { y-ín } \\
\text { boiling.water-OBL } & \text { wolf-OBL } & \text { pour.on:LGR }<\text { IMPER.PL }>-D S \\
\text { ‘... they pour boiling water on Wolf ...' (Martin 2000:388) }
\end{array}
$$

This construction, which yields subjectless clauses, presupposes the existence of an agent, yet backgrounds the agent, thereby focusing attention onto the grammatical object. Overall, the effects of the Creek impersonal plural include a movement away from cause, a greater topicality for the patient, an implicit external cause, and a valency reducing effect ( $n$-place predicate $>n$-1-place predicate), yet has no effect on the verb's transitivity.

The Creek example is of interest because in other contexts /-ho-/ is clearly a plural agreement marker, and this is its function in other Muskogean languages as well. However, the Creek impersonal passive is 'non-ascensional'. That is, it involves demotion of the agent without a corresponding promotion of the patient, which continues to function as an object. In this respect it differs from the Kaqchikel ki-passive, where available evidence indicates that the patient does become the subject. Nevertheless, we believe that a construction like that found in Creek is likely to be the diachronic source of the ki-passive.

\subsection{Kimbundu}

Haspelmath (1990:49) suggests that 'generalized-subject constructions' are an important source for the development of passives. Typically, they are called 'impersonal,' with a pronominal as its subject, usually a third person plural pronoun. Although close to a passive, generalized-subject constructions differ from the passive in that the patient is not a subject, and the agent, although backgrounded in a semantically generalizable way, still remains the grammatical subject.

However, the agreement markers associated with a generalized-subject verb may undergo change into an 'impersonal' or a 'desubjective marker' (Haspelmath 1990). This is seen quite clearly in Kimbundu, a Bantu language of Angola (Givón 1979:188, 211):

$$
\begin{aligned}
& \text { Nzua, a-mu-mono } \\
& \text { Nzua } \quad 3 \text { PSuBJ-3sOBJ-see } \\
& \text { 'Nzua, they saw him.' }
\end{aligned}
$$

Haspelmath (1990:50 citing Givón 1979:188, 211), believes two changes affect the generalized-subject construction. First, the third person plural generalized subject loses 
its 'participant status' in the clause, and second, the topicalized direct object, here $N z u a$, becomes the subject (Haspelmath 1990:50).

$\begin{array}{lll}\text { (37) Nzua } \quad \text { a-mu-mono } & \text { kwa meme } \\ \text { Nzua } \quad \text { PASs-3sSuBJ-see } & \text { by me } \\ \text { 'Nzua was seen by me.' } & \end{array}$

Critically, the third person plural subject marker is reanalyzed as a passive marker while the verb's object agreement marker is reanalyzed as the verb's subject agreement marker (Haspelmath 1990:50). That is,

Third person plural subject agreement marker $\rightarrow$ passivizing morpheme Object agreement marker (absolutive) $\rightarrow$ subject agreement marker (absolutive)

The diachronic development of a generalized-subject construction into a new passive type in the Kimbundu case parallels the Kaqchikel ki-passive construction exactly. In Kaqchikel the some instances of the /ki-/ ergative agreement marker have been transformed into a detransitivizing morpheme prefixed to the verb. Such instances of $/ \mathrm{ki}$-/ no longer function as ergative agreement markers, but as passive markers. The Kaqchikel absolutive agreement marker, which normally cross-references the object of a transitive verb, now agrees in person and number with the subject of the passive. Note also that the Kimbundu transitive verb becomes a derived intransitive as does the verb in Kaqchikel.

\section{A Comparison of the Standard Passive and the ki-Passive}

In many respects the ki-passive and the standard passive show very similar syntax. Both apply to nearly all transitive verbs in the language. ${ }^{6}$ We have found no differences in the classes of verbs which take the standard and ki-passives. Both passives occur with a full range of aspect marking and adverbial modification. There also appear to be no word order differences between the two passives. Alberto Esquit Choy, our primary consultant, comments that the two passives mean the same thing, but they sound as if they should be used in different contexts.

The differing contexts for the two passives do not seem to be readily accessible to speaker intuition, and we believe that as the corpus of analyzed Kaqchikel texts grows we may be able to get a better idea of the use of these two passives in discourse.

However, differences of grammaticality do appear in elicitation contexts when we examine the topicality of the arguments in the ki-passive, relative to the standard passive. Overall, both the agent and patient of the ki-passive appear to be restricted to old/presupposed/ topical information. The standard passive does not impose such a restriction on its arguments. This difference in topicality has a number of effects, which we explore in the following sections.

\footnotetext{
${ }^{6}$ The exceptions being a small number of equational predicates like -pajon 'to weigh'.
} 


\subsection{Focussing and the Arguments of the ki-Passive}

\subsubsection{Interrogative Focus}

Focussing either the agent or the patient of the ki-passive is severely restricted. Interrogative focus is available for subject of the standard passive but not for the kipassive.

$\begin{array}{lllll}\text { Chike } & \text { x-b'a-x } & \text { r-oma' } & \text { jun } & \text { tz' i'? } \\ \text { who } & \text { COM-bite-PASs } & \text { 3sE-by } & \text { a } & \text { dog }\end{array}$

'Who was bitten by a dog?'

STANDARD PASSIVE

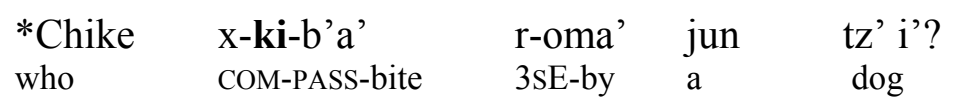

'Who was bitten by a dog?'

KI-PASSIVE

We find the same result for interrogative focus of the agent. This is possible for the standard passive (though judged a bit odd), but is completely ungrammatical for the kipassive:

$\begin{array}{llll}\text { ?Choj } & \text { oma' } & \text { x-b'a-x } & \text { ri a Juan? } \\ \text { what } & \text { by } & \text { COM-bite-PASS } & \text { the CL Juan }\end{array}$

'What was Juan bitten by?'

STANDARD PASSIVE
*Choj
what
oma'
x-ki-b'a'
ri a Juan?
what by COM-PASS-bite
the CL Juan
'What was Juan bitten by?'7
KI-PASSIVE

However it is necessary to be more precise about the interaction of interrogative focus and the ki-passive. It is ungrammatical for either the agent of the patient of the ki-passive as a whole to be interrogative. It is, however, acceptable for a determiner within the NP to be interrogative:

$\begin{array}{llllll}\text { Chike achin } & \text { x-ki-b'a' } & \text { r-oma' } & \text { jun } & \text { tz' i'? } \\ \text { which man } & \text { COM-PASS-bite } & \text { 3sE-by } & \text { a } & \text { dog } \\ \text { 'Which man was bitten by a dog?' } & & & \text { KI-PASSIVE }\end{array}$

\footnotetext{
${ }^{7}$ This is grammatical on the irrelevant reading 'What did they bite Juan because of?', where oma' is being interpreted as 'because', rather than 'by'.
} 

R-oma'
achike
tz'i'
x-ki-b'a'
ri a Juan?
3sE-by
which dog
COM-PASS-bite
the cl Juan
'Which dog was Juan bitten by?'
KI-PASSIVE

We believe the relevant notion may be 'identifiability' (or d-linking). It seems that the subject of a ki-passive must either be identifiable or be a member of a set which is indentifiable. In a case like 'which dog', the individual is not identifiable, but the set of dogs is.

\subsubsection{Negative Focus}

Negative focus for the subject patient of a ki-passive is also ruled out, though it is acceptable with the standard passive:

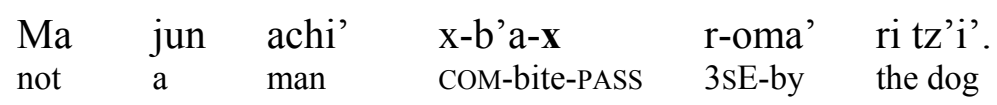

'No man was bitten by the dog.'

STANDARD PASSIVE

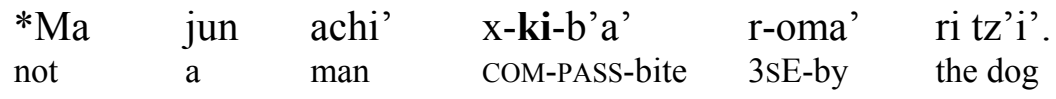

'No man was bitten by the dog.'

KI-PASSIVE

Similarly, negative focus for the agent of a ki-passive is bad, but for a standard passive it is acceptable:

$$
\begin{aligned}
& \begin{array}{llllll}
\text { Man } & \text { r-oma' } & \text { ta } \quad \text { jun } & \text { Kaqchikel } & \text { x-eleq'-äx } & \text { ri nu-ch'ich. } \\
\text { not } & \text { 3sE-by } & \text { neg a } & \text { Kaqchikel } & \text { com-steal-pass } & \text { the 1sE-car } \\
\text { 'It wasn't a Kaqchikel my car was stolen by.' } & \text { STANDARD PASSIVE }
\end{array} \\
& \text { 'My car wasn't stolen by a Kaqchikel. }
\end{aligned}
$$

$$
\begin{aligned}
& \begin{array}{lllllll}
* \text { Man } & \text { r-oma' } & \text { ta } & \text { jun } & \text { Kaqchikel } & \text { x-k-eleq'-aj } & \text { ri nu-ch'ich. } \\
\text { not } & \text { 3SE-by } & \text { NEG } & \text { a } & \text { Kaqchikel } & \text { COM-PASS-steal-TR } & \text { the 1sE-car }
\end{array} \\
& \text { 'It wasn't a Kaqchikel my car was stolen by.' KI-PASSIVE } \\
& \text { 'My car wasn't stolen by a Kaqchikel.' }
\end{aligned}
$$

The restriction on focussing arguments of the ki-passive seems to us to follow from the hypothesis that both the agent and patient of this passive are presupposed, old information. Since focussing constructions present information as either unknown or new, they are incompatible with the ki-passive.

\subsection{Definiteness and Order}

Related to this restriction are constraints on the definiteness of the subject of a ki-passive. 
There is no discernable interaction between definiteness and order in the standard passive. For the ki-passive, however, an indefinite subject preferably occurs in preverbal position:

$$
\begin{array}{lllll}
\text { Jun } & \text { me's } & \text { x-ki-b'a' } & \text { r-oma' } & \text { ri tz'i'. } \\
\text { a } & \text { cat } & \text { COM-PASS-bite } & \text { 3sE-by } & \text { the dog }
\end{array}
$$

'A cat was bitten by the dog.' KI-PASSIVE

$$
\begin{array}{lllll}
\text { ?X-ki-b'a' } & \text { jun } & \text { me's } & \text { r-oma' } & \text { ri tz'i'. } \\
\text { com-PAss-bite } & \text { a } & \text { cat } & \text { 3sE-by } & \text { the dog }
\end{array}
$$

'A cat was bitten by the dog.'

KI-PASSIVE

The difference between these two is subtler than some of the other judgments. On some occasions sentences of this type (i.e. verb-initial indefinite subject ki-passive) were rejected. On other occasions, they were accepted after some hesitation. Though apparently not completely ungrammatical, they are never volunteered, and seem to be less natural and acceptable than the subject-initial version of such sentences.

There is no comparable difference between verb-initial and subject-initial versions of basic passive sentences with indefinite subjects:

$$
\begin{array}{lllll}
\text { Jun } & \text { me's } & \text { x-b'a-x } & \text { r-oma' } & \text { ri tz'i'. } \\
\text { a } & \text { cat } & \text { COM-bite-PAss } & \text { 3sE-by } & \text { the dog }
\end{array}
$$

'A cat was bitten by the dog.'

STANDARD PASSIVE

$$
\begin{array}{lllll}
\text { X-b'a-x } & \text { jun } & \text { me's } & \text { r-oma' } & \text { ri tz'i'. } \\
\text { com-bite-pass } & \text { a } & \text { cat } & \text { 3sE-by } & \text { the dog }
\end{array}
$$

'A cat was bitten by the dog.'

STANDARD PASSIVE

Broadwell (2000) shows that obligatory preverbal order for subjects is a response to marked combinations of features. In this case, we believe the markedness is the combination of indefinite and presupposed, old information.

Indefinite and presupposed might initially be thought to be opposites, but this is not necessarily so. The relevant restriction for the ki-passive is identifiability, while the restriction on the definite article is previous mention. An indefinite argument is possible for the ki-passive in the case where an individual has not been previously mentioned, but belongs to an identifiable set.

\subsection{Generic Patients and the ki-Passive}

Generic patients appear to be incompatible with the ki-passive. In the following example, the transitive has a non-specific object. It is possible to form a corresponding standard passive, but the ki-passive is blocked. 


$$
\begin{aligned}
& \text { A Juan n-r-ajo' } \quad \text { jun ch'ich. } \\
& \text { cl Juan inc-3sE-want a car } \\
& \text { 'Juan wants a car.' (generic reading) }
\end{aligned}
$$$$
\text { TRANSITIVE }
$$

$\begin{array}{lllll}\text { Jun } & \text { ch'ich } & \text { n-ajow-äx } & \text { r-oma' } & \text { a Juan. } \\ \text { a } & \text { car } & \text { INC-want-PASS } & \text { 3sE-by } & \text { cl Juan }\end{array}$

'A car is wanted by John.' (generic reading)

STANDARD PASSIVE

$$
\begin{array}{lllll}
* \text { Jun } & \text { ch'ich } & \text { ni-k-ajo' } & \text { r-oma' } & \text { a Juan. } \\
\text { a } & \text { car } & \text { INC-PASS-want } & \text { 3sE-by } & \text { cl Juan }
\end{array}
$$

'A car is wanted by John.' (generic reading) KI-PASSIVE

This restriction follows if the arguments of the ki-passive must be previously established, topical noun phrases, since genericity is typically incompatible with topicality.

\subsection{Inanimate Agents}

Animacy is also relevant to the topicality of the arguments in the ki-passive. There is in general no restriction against inanimate subjects of transitive verbs in Kaqchikel:

$$
\begin{aligned}
& \text { Ri che' x-u-tzäq } \\
& \text { the tree com-3sE-knock:down } \\
& \text { 'The tree knocked down the house.' }
\end{aligned}
$$

TRANSITIVE

Inanimate agents are permissable in the standard passive, but not in the ki-passive: ${ }^{8}$

$\begin{array}{llll}\text { Ri ja'y } & \text { x-tzaq } & \text { r-oma' } & \text { ri che'. } \\ \text { the house } & \text { COM-knock:down:PASS } & \text { 3sE-by } & \text { the tree }\end{array}$

'The house was knocked down by the tree.' STANDARD PASSIVE
*Ri ja’y
x-ki-tzäq
r-oma'
ri che'. the house COM-PASS-knock:down 3sE-by the tree
'The house was knocked down by the tree.'
KI-PASSIVE

There is no animacy restriction on the patient of either passive:
Ri wä'y
x-ki-tij
r-oma'
ri achin.
the tortilla COM-PASS-eat 3sE-by

'The tortilla was eaten by the man.'

KI-PASSIVE

\footnotetext{
${ }^{8}$ Compare the impersonal passive in Dutch. Kirsner (1976) notes that in Es werd gefloeten. 'It was whistled', the whistling must have been done by a human and not by 'birds, teakettles, or the wind.'
} 


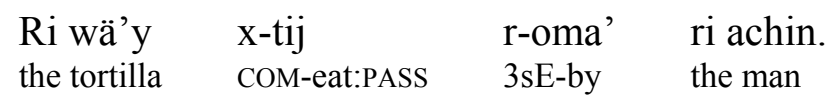

'The tortilla was eaten by the man.'

STANDARD PASSIVE

Using the approach of Aissen (1997, 1999a, 1999b) we hypothesize that the agent of the ki-passive outranks the patient in obviation status. But proximate inanimates are in general strongly marked relative to obviative inanimates, and in a number of languages they are ungrammatical. Although we will not formalize the OT treatment here, we believe the ki-passive is suboptimal relative to the standard passive because it involves the assignment of proximate to an inanimate.

\subsection{A Remaining Puzzle: 3rd-person Plural Subjects}

There is at least one more restriction on the ki-passive: the subject of a ki-passive cannot be 3rd person plural. There is no equivalent restriction on the subject of a standard passive:

$$
\begin{array}{llcll}
\text { A Juan y Maria } & \text { x-e-b'a-x } & \text { r-oma' } & \text { jun kumätz. } \\
\text { CL Juan and Maria } & \text { COM-3PA-BITE-pass } & \text { 3sE-by } & \text { a snake } \\
\text { 'Juan and Maria were bitten by a snake.' } & & \text { STANDARD PASSIVE }
\end{array}
$$

$$
\begin{array}{lcccl}
\text { *A Juan } & \text { y Maria } & \text { X-e-ki-b'a' } & \text { r-oma' } & \text { jun kumätz. } \\
\begin{array}{lll}
\text { CL Juan } \\
\text { and Maria }
\end{array} & \text { COM-3PA-PASS-bite } & \text { 3sE-by } & \text { a snake } \\
\text { 'Juan and Maria were bitten by a snake.' } & & \text { KI-PASSIVE }
\end{array}
$$

It seems that in some way, this restriction must be related to the fact that $/-\mathrm{ki}-/$ also functions as a $3^{\text {rd }}$ person plural. But /-ki-/ marks a third person plural ergative subject and the subject of examples like (60) should trigger absolutive agreement, which is /-e-/.

There is no general problem with the combination of $3^{\text {rd }}$ person plural ergative and absolutive morphology in the active:

$$
\begin{array}{lll}
\begin{array}{l}
\text { Ri alab'oni' } \quad \begin{array}{c}
\text { x-e-ki-tij } \\
\text { com-3pA-3pE-eat }
\end{array} \\
\text { the boys }
\end{array} & \begin{array}{l}
\text { ri wä'y. } \\
\text { the tortilla }
\end{array} \\
\text { 'The boys ate the tortillas. } &
\end{array}
$$

It is certainly possible to stipulate this as a property of the ki-passive morpheme, but we do not have an explanation of why such subjects should be forbidden.

\footnotetext{
${ }^{9}$ Overt plural morphology on nouns is limited to humans and some animals, so ri wä'y will be interpreted as either 'tortilla' or 'tortillas', depending on the agreement morphology it triggers.
} 


\subsection{Summary}

The following table summarizes the differences between the active, the standard passive, and the ki-passive.

\begin{tabular}{llll} 
& active & standard passive & ki-passive \\
\hline interrogative agent & yes & yes & no \\
interrogative det of agent & yes & yes & yes \\
interrogative patient & yes & yes & no \\
interrogative det of patient & yes & yes & yes \\
negative focussed agent & yes & yes & no \\
negative focussed patient & yes & yes & no \\
inanimate agent & yes & yes & no \\
generic patient & yes & yes & no \\
postverbal indefinite subject & no & yes & marginal \\
$\mathbf{3}^{\text {rd }}$ plural patients & yes & yes & no
\end{tabular}

\subsection{Connecting Synchrony and Diachrony}

We see a connection between the synchronic properties of the ki-passive and its diachronic origin. In languages with impersonal constructions, such as Creek, the agent is always strongly defocussed and treated as background information. In general, the backgrounding of the agent is accompanied by an corresponding increase in the topicality of the patient. Thus both the agent and the patient in an impersonal are old information, differing from each other in relative prominence.

The restrictions on the use of the ki-passive have a clear connection with its diachronic origin in an impersonal construction. Impersonals shift the informational focus of a clause without changing its valence. The Kaqchikel ki-passive maintains the informational perspective of the impersonal, accompanied by valence reduction. Thus while the syntactic structure has changed from transitive to intransitive, the informational content of this construction has remained the same.

\section{Conclusion}

The existence of languages with multiple passives has been known for some time (e.g. Dutch, Kirsner 1976; Irish, Noonan 1994; Akatek, Zavala 1997), but it seems to us that generative theory has not fully appreciated their significance. The focus of most explanation has been the relation-changing nature of the passive, and on developing models that predict just these relation changes.

But a language like Kaqchikel can have two passives that are syntactically identical, differentiated from each other by the relative topicality or obviation status of their arguments. To put the question bluntly, where does this kind of information go in a grammar? If passive involves movement to a functional projection, how do the two 
different passive morphemes convey differing information about the relative topicality of their arguments?

From our perspective, these facts point toward the need for a constructional approach to the passive, like that advocated by Webelhuth and Ackerman (1998). In such an approach, the universal archetype of the passive may be supplemented by additional morphological, semantic, and discourse restrictions. While we have learned much from the search for universality in linguistic rules, we must not forget that insight can also come from the careful study of particularities. 


\section{References}

Aissen, Judith. 1999a. Agent choice and inverse in Tzotzil. Language 75:451-485.

- 1999b. Markedness and subject choice in optimality theory. Natural language and linguistic theory 17:673-711.

1997. On the syntax of obviation. Language 73:705-750.

Anderson, Stephen R. 1992. A-morphous morphology. Cambridge: Cambridge University Press.

Beard, Robert. 1995. Lexeme-morpheme base morphology Albany, NY: State University of New York Press.

Broadwell, George Aaron. 2000. Word order and markedness in Kaqchikel. Proceedings of the LFG 2000 Conference. http://csli-publications.stanford.edu/LFG/5/lfg00toc.html.

Dayley, John P. 1981. Voice and Ergativity in Mayan Languages. Journal of Mayan Linguistics 2(2):3-82. 1978 Voice in Tzutujil. Journal of Mayan Linguistics 1(1):20-52.

García Matzar, Pedro (Lolmay), and José Obispo Rodríguez Guaján (Pakal B’alam). 1997. Rukemik ri Kaqchikel Chi’: Gramática Kaqchikel. Guatemala City: Editorial Cholsamaj Okma.

Givón, Talmy. 1979. On understanding grammar. New York: Academic Press.

Haspelmath, Martin. 1990. The grammaticization of passive morphology. Studies in Language 14: 25-72

Kirsner, Robert. 1976. On the subjectless "pseudo-passive" in Standard Dutch and the semantics of background agents, in Charles Li, ed. Subject and Topic. pp. 385416. New York: Academic Press.

Martin, Jack B. 2000 Creek voice: beyond valency. In RMW Dixon and AY Aikhenvald, eds., Changing valency: Case Studies in transitivity. pp. 375-402. Cambridge: Cambridge University Press.

Noonan, Michael. 1994. A tale of two passives in Irish, in Paul Hopper \& Barbara Fox, eds, Voice: Form and Function, Amsterdam: John Benjamins.

Webelhuth, Gert and Farrell Ackerman. 1998. A theory of predicates. Stanford: CSLI.

Zavala, Roberto. 1997. Functional analysis of Akatek voice constructions. International Journal of American Linguistics 63:439-74.

Authors' contact information:

submitted: May 3, 2002

George Aaron Broadwell

g.broadwell@albany.edu

Lachlan Duncan

1d4391@albany.edu

Department of Anthropology

University at Albany, SUNY

Albany, NY 12222 USA 